\title{
Effect of Gradient Alloying on Photoluminescence Blinking of Single $\mathrm{CdS}_{\mathrm{x}} \mathrm{Se}_{1-\mathrm{x}}$ Nanocrystals
}

Swayandipta Dey ${ }^{\dagger}$, Shutang Chen ${ }^{\dagger}$, Sravan Thota ${ }^{\dagger}$, Md R. Shakil ${ }^{\dagger}$, Steven L.Suib ${ }^{\dagger \#}$, Jing Zhao $\#^{* *}$

${ }^{\dagger}$ Department of Chemistry, University of Connecticut, 55 North Eagleville Rd, Storrs, CT, 06269-3060, USA

${ }^{\#}$ Institute of Materials Science, University of Connecticut, Storrs, CT, 06269-3136, USA

* Address correspondence to: jing.zhao@uconn.edu (J. Z.) 

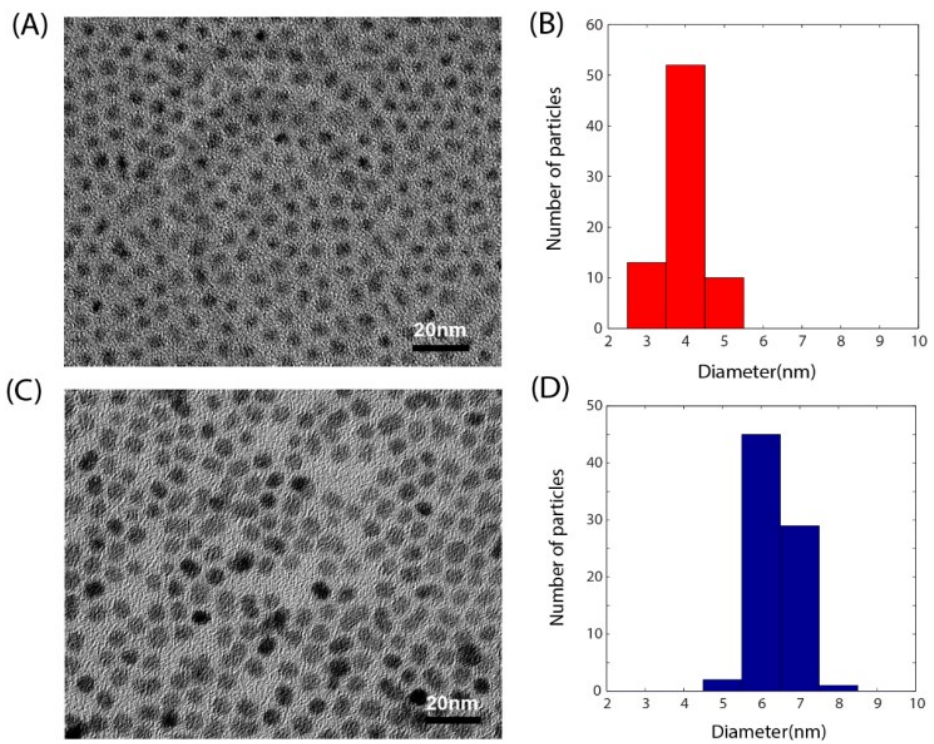

Figure S1.(A,C) TEM images of CdSSe NCs of two different sizes with mean diameter of $3.96 \pm 0.5 \mathrm{~nm}$ and $6.5 \pm 0.75 \mathrm{~nm}$, respectively. (B,D)Corresponding size distributions of the NCs showing a fairly narrow distribution of the samples from two different synthesis. 
Table S1. Powder XRD data showing (hkl) vs $2 \theta$ values for the wurtzite alloyed CdSSe NCs at two different growth times $\left(\mathrm{CdS}_{0.14} \mathrm{Se}_{0.86}, 1 \mathrm{~min}\right.$ and $\left.\mathrm{CdS}_{0.24} \mathrm{Se}_{0.76}, 10 \mathrm{~min}\right)$

\begin{tabular}{|l|l|l|l|l|}
\hline (hkl) & Bulk CdSe(00-002-0330) & Bulk CdS(00-002-0549) & $\mathbf{C d S}_{\mathbf{0 . 1 4}} \mathbf{S e}_{\mathbf{0 . 8 6}}$ & $\mathbf{C d S}_{\mathbf{0 . 2 4}} \mathbf{S e}_{\mathbf{0 . 7 6}}$ \\
\hline$(100)$ & 23.77 & 24.92 & 23.87 & 24.06 \\
\hline$(002)$ & 25.28 & 26.59 & 25.08 & 25.40 \\
\hline$(101)$ & 26.91 & 28.31 & 26.65 & 27.09 \\
\hline$(102)$ & 35.02 & 36.80 & 34.76 & 35.32 \\
\hline$(110)$ & 41.78 & 43.92 & 41.76 & 42.10 \\
\hline$(103)$ & 45.59 & 48.10 & 45.53 & 45.73 \\
\hline$(112)$ & 49.53 & 51.91 & 49.40 & 49.84 \\
\hline
\end{tabular}



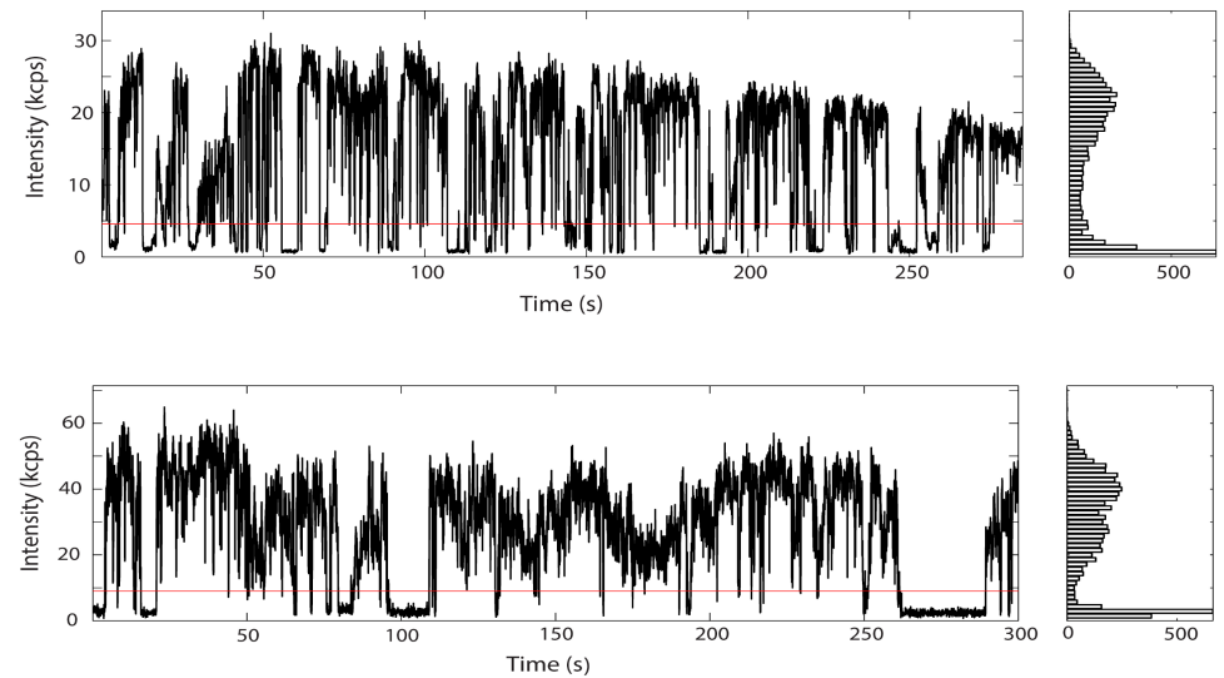

Figure S2.Representative PL intensity time trajectories of single CdSSe NCs with the corresponding histograms of intensity distribution. 

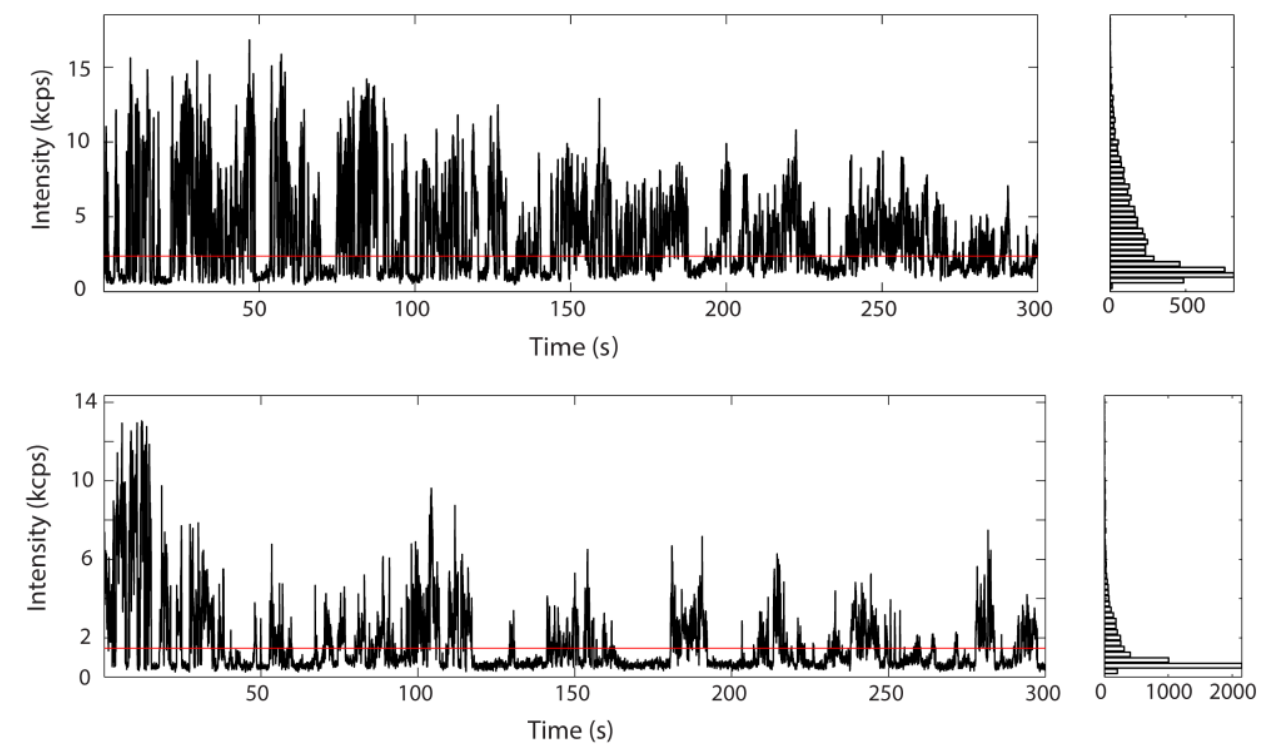

Figure S3. Representative PL intensity time trajectories of single CdSe NCs with the corresponding histograms of intensity distribution. 


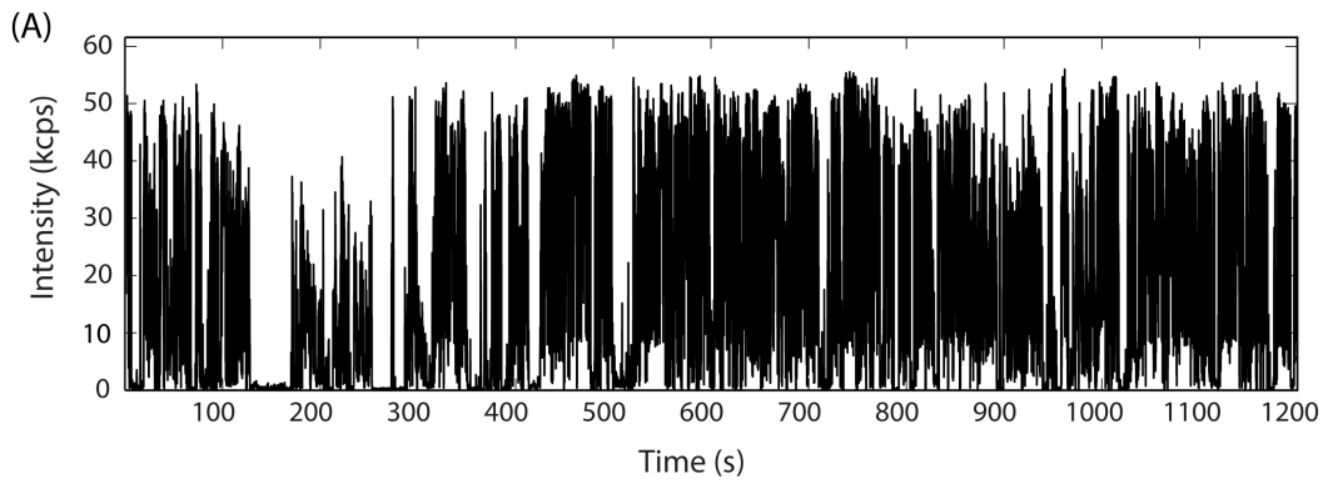

(B)

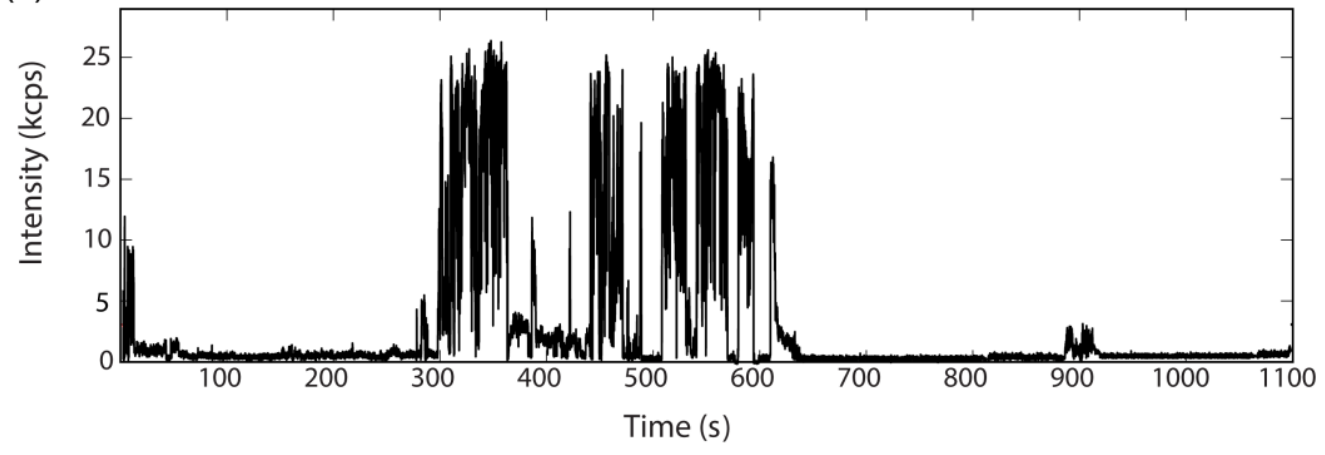

Figure S4. PL intensity trajectories of single (A) CdSSe and (B) CdSe NCs at long acquisition times. The CdSSe NC shows no considerable change in their intensities as compared to $\mathrm{CdSe} \mathrm{NC}$. 


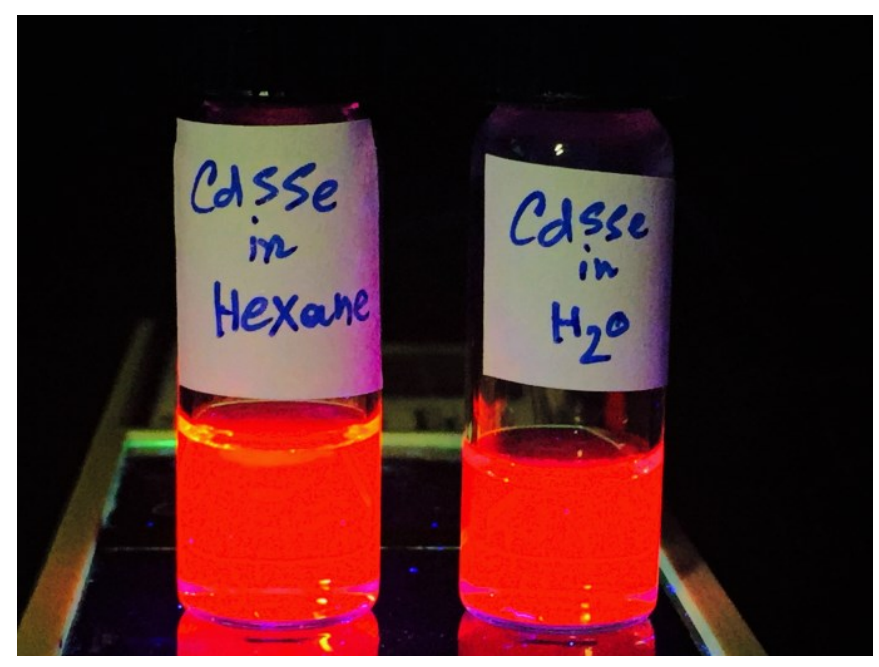

Figure S5. Pictures of CdSSe NCs before (dispersed in hexane) and after phase transfer (dispersed in nanopure water), excited using a handheld UV lamp. The NCs stay well dispersed in water even after 3-6 months of ligand exchange (under storage conditions at $4^{\circ} \mathrm{C}$ ). 